\title{
Shan Noises, Burmese Sound: Crafting Selves through Pop Music
}

\author{
Amporn Jirattikorn \\ Ph.D. candidate \\ Department of Anthropology \\ University of Texas at Austin
}

The woman at the guesthouse where I stayed in Mandalay was humming Sai Htee Saing's tunes while sweeping the floor. An English bookshop owner in Rangoon played Sai Htee Saing's "Tabawa," an album that came out in the seventies, on his old boombox. Walking through the streets of a suburb of Rangoon, I saw a group of young men jamming in front of their house. The songs they were playing were those of Sai Htee Saing's hits.

Rangoon and Mandalay are the two biggest cities in Burma ${ }^{1}$ where one can expect to hear a lot of hip-hop, as it is becoming a trend among the younger generation. To hear that Sai Htee Saing's songs from the eighties are still alive, I can't help but wonder what it means to a fraillooking Shan man who is now in his 50 s. In a country where polity and economic opportunities operate along racial lines, and ethnic minorities experience prejudice held by the Burman majority ${ }^{2}$, the popularity an ethnic Shan singer has gained among Burman audiences begs several questions. What it is that Sai Htee Saing has that charms audiences so? How has he managed, through this musical practice, to serve the interests of his fans from different ethnic backgrounds? Sai Htee Saing is not the only ethnic Shan artist who has become popular nationwide. Sai Sai Mao, also an ethnic Shan singer, is credited as one of the two most famous Shan artists in Burma's music industry. His recent album from a live concert in 2004 could be heard everywhere when I visited Burma during August - October 2005. Because it was released in the video CD format, it was shown repeatedly on many restaurant TV sets, as well as on the long distance buses that link Rangoon or Mandalay to other parts of the country.

This paper focuses on the songs of these two Shan artists, Sai Htee Saing and Sai Sai Mao. Both have challenged the dominant social group, the Burman, who have had more access to and control over the means of cultural production and dissemination. These two Shan singers have sung in Burmese for three decades, and become two of the most famous singers in Burma's music industry. While performing in the Burmese language to cater to a Burmese speaking audience, their songs often reflect on life in Shan state, introducing listeners of the Burman majority to Shan culture. Audiences express their appreciation in songs of these two artists in various ways yet tend to stress that these two singers have a Shan accent while singing in Burmese--and that they love that. Two points can be made here: first,

\footnotetext{
1 The name of the country was known as Burma until 1989. The current military regime changed the name of Burma to Myanmar because of its perceived colonial associations. However, political parties both within and outside Burma refuse to use the new name as the changes were made without consultation with the populace. Instead of "Myanmar", the term "Burma" will be used throughout this paper.

The term "Burman" is used here to refer to ethnic "Burman" who comprise about $68 \%$ of the population in Burma. The term "Burmese" is used in a more general and broader sense, when referring to the Burmese language, state, culture or song.
} 
a distinctive feature of these two Shan artists lies in their accented voice, and second, they often sing about life in Shan state ${ }^{3}$, offering listeners a glimpse of what it means to be Shan in a country dominated by the Burman majority. My contention is that both the accent and the portrayal of Shan life in song lyrics are a form of self-representation. I seek to explore such forms of self-representation to argue that ethnic Shan singers utilize Burmese language to redefine their own ethnic identity, in the process helping to construct the Shans' place in the Burmese national imaginary. I ask two major questions. First, what specific forms does this self-representation take? And what kinds of symbols are used by these two Shan artists to perform or portray their Shan "selves"? Second, who is the audience and whose interest does such self-fashioning serve?

In trying to understand the practice of self-fashioning/self-representation, my theoretical perspective is framed around Mary Louise Pratt's concept of contact zone. In Imperial Eyes, Pratt (1991) talks about the "contact zone," which is an attempt to invoke the spatial and temporal co-presence of subjects previously separated by geographic and historical disjunctures, and whose trajectories now intersect. A contact zone emphasizes how subjects are constituted in and by their relations to each other. Pratt discusses narratives of the contact zone, which she calls "autoethnographic expression," where colonized subjects represent themselves in ways that engage with the colonizer's own terms. Borrowing from Pratt, I seek to analyze how the songs of two Shan artists can be seen as autoethnographic texts in response to or in dialogue with those of Burmese representations. It is in these songs that we can see how Shan artists select and adapt dominant discourse about them to their own task of creating themselves. In this article, I wish to look, not only at the production of selfrepresentation, but also how self-fashioning is perceived by audience of the dominant group. This paper, therefore, aims to be both an analysis of the self-representation of Shan ethnic identity, as well as an ethnography of audience reception, looking at how the concept of selffashioning by Shan ethnic minority feeds into the imagination of the Burman majority.

\section{The Burmese Musicscape}

Burmese pop music covers a wide range of music, from rock and sentimental love songs to hip-hop. Burmese pop generally refers to domestically produced, Westerninfluenced popular music sung in Burmese. Before the arrival of the "rock boom" in the 1960s, the Burmese musical landscape can be seen and heard in two streams: traditional Burmese music performed in association with stage shows such as local plays, puppet shows, dance-drama and opera, and the western-style music such as jazz and cha cha cha, performed in urban nightclubs. The former was also broadcast on the state-run radio, which was formed in 1946 (Aung Zaw 2004). After the military government led by General Ne Win seized power in 1962, it began to ban clubs featuring western-style music along with beauty contests, horse racing, and dance competitions. These were all seen as cultural pollution. In the late 1960s, the regime set up a censorship board for the Burmese Broadcasting Service (BBS) radio music program. The board set certain criteria for the selection of songs; in most cases, it rejected Western-style compositions.

\footnotetext{
3 Burma is divided into seven states and seven divisions. While divisions are predominantly Burman, states are home to particular ethnic minorities. Seven states are Chin, Kachin, Karen (Kayin), Karenni (Kayah), Mon, Arakan (Rakhine), and Shan states.
} 
In the 1960s, rock and roll began to enter Burma and Burmese youth began to imitate rock stars such as the Beatles, Elvis Presley, Cliff Richard and the Shadows. They performed Western versions of rock music in local venues such as universities or tea shops. Burmese musicians later developed "cover versions" of Western rock music by utilizing Burmese lyrics and offering local content. The government quickly banned this Western style pop music, criticizing it as cultural pollution, promoting "un-Burmese sounds, un-Burmese expressions, and un-Burmese state manners" (Maung Tin Mya 1984: 46). Because the government banned this western style music and the censorship board refused to play their cover songs on the stateowned radio station, Burmese musicians looked for alternative ways to reach the audiences. They turned to private promoters. The emergence of private promoters coincided with the new technology of reel-to-reel audio tape that arrived in Burma in the 1970s. Tape became an alternative for artists who had been denied access to state-run radio. Before the arrival of reelto-reel technology, all songs disseminated through radio were in mono. But the new technology contributed to better audio quality, producing the music in stereo. Thus when the censorship board refused to play their cover songs, young musicians recorded those songs in promoters' studios equipped with high fidelity stereo sound-recording facilities and marketed the reel-toreel albums, labeling them "stereo music" to differentiate them from the Burmese Broadcasting Service's mono recordings (Maung Tin Mya 1984). It was at this point that Burmese pop music became known as "stereo songs" in contrast with the "mono" BBS productions. Initially, this new culture only had a limited audience, particularly in the form of urban educated youth. The non-urban audiences who could not afford reel-to-reel players still listened to the music that had been scrutinized by the censorship board, and since the board rejected Western-style compositions, the music played on the radio was traditional Burmese music.

Pop music became an important cultural expression of young people against the regime's suppression of Western influence. While rock was an ideology, and the 1970s saw Burmese musicians began to experiment with the new tunes, most of them produced little more than Burmese adaptations of western hits, or they sang in English. Against this background, in 1973 a group of students at Mandalay University set up a band called Thabawa Yinthwenge (lit, children of nature), but they are most well-known as "The Wild Ones." The band consisted of five members, following a standard rock lineup with Sai Htee Saing, lead singer and rhythm guitar, Sai Khamti, the drummer, Joni, bluesy lead guitar, Jackson, bass, and Sai Khamlek, a composer and a nonperforming member. The unique aspect of their music was that they composed their own songs, offering a new style of original composition. The Wild Ones became a phenomenon. The success of the Wild Ones led to the flourishing of "own tunes" bands and songs, which took their place amidst the prevalence of cover versions. As Maung Tin Mya reports in 1984 that more than $75 \%$ of all pop songs were actually foreign tunes with Burmese lyrics (Maung Tin Mya 1984). The emergence of the Wild Ones with its original compositions contributed to the scene to the point when Burmese pop music broke into two forms of composition, "copied tunes" and "own tunes". These two terms became a common use among both Burmese musicians and audiences.

While reel-to-reel technology contributed to the emergence of Burmese pop/rock music, the audience was limited to only urbanites. The arrival of cassette technology at the turn of the 1970s, however, helped Burmese pop music spread to a wider audience. In early 1980s, Maung Tin Mya (1984) reports that there were four well-equipped major studios for recording albums as well as small studios fitted with reel-to-reel and cassette recorders for copying songs from master tapes onto cassette tapes for retail sales. A one-hour tape with 
music sold for about US\$5 and a top vocalist could sell as many as 30,000 copies (1984: 46). Despite government calls to prevent "cultural pollution by alien influence," rock bands proliferated.

The advent of cassette technology accorded well with Burmese tea culture. At tea shops, Burmese males would sit for hours, chatting about everything. In addition to selling tea, shop owners would play "stereo" songs to attract more customers. Customers could bring their favorite tapes to play. Aung Zaw writes that it was common for teashop owners to invest in the installation of powerful speakers so that they could blast out the latest album in order to draw more customers than their competitors (Aung Zaw 2004: 45). Amidst this background, Sai Htee Saing and the Wild Ones became the most famous band of the 1980s and their songs could be heard in every teashop in town. In addition to tea culture venues, Sai Htee Saing's songs were performed every night outside girls' dormitories on university campuses. It was a popular practice among university students during the 1980s-90s for amateur singers to stay up the whole night singing and playing music to woo female students in front of girl's dormitories. Some amateur singers who performed this serenade about a decade ago recall that female students often threw a small piece of paper out the window requesting Sai Htee Saing's hit songs. Those who played Sai Htee Saing's songs in turn would get food and snacks sent by admiring female audiences - via campus security guards. In addition, since female students could not come out from the dormitories after $6 \mathrm{pm}$., they communicated by turning lights in their room on and off as a sign of their appreciation.

Since its earlier days, Burmese pop music has been associated with a certain sort of modernity. The development of Burmese pop music can not be viewed in isolation from the military dictatorship that forms an invisible backdrop for this music of teenage pleasures. The dichotomy of stereo/mono contrasts musical styles of pop/rock and traditional forms of staged shows as well as illustrating contrastive meaning of modernity and tradition. The distinction also divides the audience into young and old generations. In terms of content, pop music breaks with traditional Burmese music by celebrating romantic love in the context of the urban city. Despite such dichotomies, however, pop/rock music has become a part of popular entertainment alongside Burmese traditional music, and outdoor "stereo staged shows" have been the most entertaining component of Burmese religious festivals since the 1970s (Min Zin 2002).

\section{Two Shan Singers and One Songwriter in the Burmese Music Industry}

During the time that young Burmese musicians were urged to catch up with the rock and roll trend, two Shan boys who were to become two of the most influential figures in the Burmese music industry were studying at Mandalay University. Sai Khamlek, a medical student, started to compose Shan songs even before entering university. He stated he was compelled to write Shan songs for the reason that there were very few "modern" songs for Shan people to sing while there were many songs sung in Burmese language. He composed his first few songs without knowing theory, notes or how to play a guitar (Sai La 1997). At Mandalay University, Sai Khamlek met Sai Htee Saing and the two became involved with the Shan literature movement that began after 1962, when the military government banned Shan language in school. Fearing language loss, Shan intellectuals set up alternative schools in Shan state during the summer to teach Shan language to illiterate villagers and children. As part of this literacy movement, they composed songs in Shan language and used their guitars to foster language learning. They saw pop music as a language teaching tool. 
During 1970-73, Sai Khamlek composed several Shan songs on guitar which were not recorded but sung and came to be known widely by Shan people. Many of his songs written during that time were later recorded by various artists and have been sung occasionally on stage during festivals. However, as it was customary that Burmese singers would borrow freely from various sources, it is said that some of his songs were taken up by Burmese singers and sung using Burmese lyrics. Some audiences, not aware that the songs were originally written by Sai Khamlek, turned to accuse him of copying melodies from Western sources, as almost all of Burmese pop songs at that time were actually foreign tunes with Burmese lyrics. It was at this point that Sai Khamlek decided to write original Burmese songs, and the band the Wild Ones was formed with Sai Htee Saing as lead singer

While in the 1970s the Wild Ones was enjoying popularity among Burmese speaking audience inside Burma, on the other side of the border, Sai Sai Mao, who later became the most popular singer of Shan pop music, started recording his first few albums in Shan language in Thailand. It is interesting that the history of Shan pop music is associated with Thailand to a large degree. In Thailand, there are Shan communities that settled in northern Thailand, especially in the Mae Hong Son area, for more than 100 years (see Eberhardt 2006). During 1968-1969, Sai Sai Mao traveled extensively back and forth between Burma and northern Thailand because his grandfather traded goods between Taunngyi and northern Thailand. In 1968, Sai Sai Mao was invited by Radio Thailand, Chiang Rai to perform on the Shan language program. It was the same procedure as when a radio program in Burma invited singers to perform in a live performance, then recorded it and played it repeatedly on the program. Sai Sai Mao came to be known widely by Shan communities both in Thailand and Burma through this channel. A Shan man in his 50s who now lives in Thailand recalled that when he was young, he looked forward to hearing Sai Sai Mao's songs broadcast via Radio Thailand which could reach as far as Shan state, Burma.

Between 1973 and 1976, Sai Sai Mao was associated with SSAE (Shan State ArmyEastern) and was given financial support from his boss to record a Shan music album. He came to Bangkok to record his first album which includes the famous song Likhommai Panglong (The Promises of Panglong). Likhommai Panglong talks about the Panglong Agreement signed in 1947, in which the Burmese representative promised the Shan and other ethnic groups the right to secede from the Union of Burma after a period of ten years. The song calls for the Burmese government to make good on the promises made in the agreement and condemns the regime as a betrayer of the Shan ethnic minority. Although most of Sai Sai Mao's songs recorded later were love songs, Likhommai Panglong became his trademark song and established Sai Sai Mao as a "nationalist" Shan singer. During his years of association with Shan State Army-Eastern, which had one of its bases near northern Thailand, Sai Sai Mao recorded his first few albums in Chiang Mai, Thailand. In 1976, he surrendered to the Burmese government and started a career as a professional singer, recording albums in Burma both in Shan and Burmese language (interview with Sai Mao, September 2005). Most of Sai Mao's songs are taken from Thai or Chinese hit tunes, and sung in Shan lyrics. Lyrics are often written by him or his brother. Sai Sai Mao's songs sung in Burmese are often translated from his Shan versions. Throughout his career as a singer, he has released more than 10 albums in Burmese. Although he has never been as successful as Sai Htee Saing in singing Burmese songs, his recent album, which is from a live concert at which he invited 
many Burmese artists to sing his legendary songs, was very popular when it came out in 2005.

Sai Sai Mao's and Sai Htee Saing's lives as Shan singers in the Burmese music industry provide contrasts and similarities. Both are ethnic Shan who strive to be successful amidst the dominant social group, the Burman, who have had more access to and control over the means of cultural production and dissemination. Both have been involved in the Burmese music industry for more than three decades. Over the past 30 years, Sai Htee Saing has produced over 60 albums, including 10 in his native Shan language. Sai Sai Mao, on the other hand, has produced more albums in Shan language than in Burmese language and has gained more popularity among Shan audiences. In terms of musical styles, while Sai Htee Saing sings original songs composed by Sai Khamlek, Sai Sai Mao often sings songs that borrow tunes from various sources. In terms of content, though most of their songs revolve around romantic expression of love, both often sing about various aspects of being Shan.

It is crucial to note that in Burma, there are many practices that keep old songs alive. Min Zin notes that albums of newly produced easy-listening cover songs and updated renditions of 10-20-year-old songs are always on the top-ten list of the Burmese music industry (Min Zin 2002: 25). This can be seen in the huge success of Sai Sai Mao's newly produced cover versions of his legendary songs, sung by himself and other well-known Burmese artists. In the same way, many of Sai Htee Saing's old albums from the seventies and eighties are still selling well today. Moreover, as mentioned earlier, there is the popular practice among university students of getting together to perform every night outside girls' dormitories. The simple arrangement of Sai Htee Saing's and Sai Sai Mao's songs that they play are said to be easy to play on guitar. By these ways, old lyrics are kept alive through years of singing in front of girls' dormitories, jamming by amateur musicians, and through cover versions by other Burmese artists. The re-appearance of songs in Burmese musical practice helped to make Sai Htee Saing and Sai Sai Mao ineradicable figures in the Burmese public memory.

\section{Performing Selves, Performing Shan-ness}

Sai Htee Saing and Sai Sai Mao do not hide the fact that they are Shan. They both often wear Shan costumes on the stage. They use Shan names, indicated by "Sai" at the beginning of their (male) names (a Shan woman's name begins with "Nang"). Their songs often talk about aspects of being Shan in a country ruled by the Burman. In terms of accent, Sai Htee Saing states that Burman audiences often say to him that his accent is "neh neh we deh" meaning it is a little far from native accent. Although he tries to sing like a native, but for the Burman audiences he still seems obviously Shan (Interview with Sai Htee Saing, September 2005). As for Sai Sai Mao, some Burman audiences say that his accent is even "mya mya we deh" meaning it is very far from that of a native speaker of Burmese. A number of my informants state that they think a Shan accent is "simple" and "cute," and therefore they appreciate Shan singers singing with an accent. The success of Sai Htee Saing and Sai Sai Mao among the majority of Burman audience begs many questions, one of which involves "words," "voices" and ethnicity. It is crucial to note here that when I discuss about words in music, I do not refer only to lyrics as poems or literary objects. Although many would regard the study of popular music in isolation from its musical structure as problematic, I maintain that in listening to the lyrics of pop songs we do not hear only lyrics as poems or literary objects which can be analyzed entirely separately from music. As Frith 
argues that in listening to the lyrics of pop songs we actually hear three things at once; words, rhetoric and voices. When we hear words being used in a musical way, we hear words being sung in human tones which are themselves "meaningful," signs of persons and personality (Frith 1996: 159). My contention is that words matter to people, and that they are central to how pop songs are heard and evaluated. In what follows, I present a collection of hit song lyrics by Sai Htee Saing and Sai Sai Mao. The song lyrics here are selected because of their thematic stories about Shan people. I read the interpretation of these songs by the Burman audiences, looking at how the signs and symbols of Shan-ness are consumed and comprehended by the audiences in a variety of contexts and how they bring diverse frames of interpretation to the songs. Although Sai Khamlek's lyrics which discuss being Shan represent less than $20 \%$ of his entire collection, all of the songs analyzed here are well known among audiences. It is the same for those of Sai Sai Mao.

Sai Htee Saing's first hit, that went on to become his greatest hit, is Mandalay Yao, Shan Ta Yao (A Shan Living in Mandalay). It was written by Sai Khamlek in 1979. The lyrics of this song in English translation are as follows:

Every time I enter the Mandalay market, a horse cart driver asks me

"Do you want to go to the big pagoda?"

Every street I walk down, the kids mock me

with the sound of the Shan drum, "nong nong nong"

I don't want to change my position

I am proud of being a hill person.

However, it's not easy to be a Shan living in Mandalay.

Whenever I am near movie theaters,

They ask me "do you want to see action movies?"

When I go to the teashop, order a cup of tea,

I am asked "do you take a lot of sugar?"

Whenever I hang around the campus, girls look at my Shan attire.

They smile.

Whenever at the hospital, I am roundly upbraided by the nurses.

However you discriminate against me

I will embrace those old stories with my love

I don't swap my identity with others

I am proud of being a hill person

But it's not easy to be a Shan living in Mandalay

I have shown the girls that the love of a Shan is no less than that of a Burman

However, the girl's parents did not give me favor.

Because I don't have money.

And because I am not successful,

I have no place of refuge.

The life and experience of a Shan,

Who tries to settle in Mandalay,

Is the same as before.

I want to be proud of being a hill person.

However, it's not easy to be a Shan living in Mandalay.

A Shan in Mandalay is still smiling.

(composed by Sai Khamlek 1979, translated by the author) 
Here Sai Khamlek talks about his personal experience as an ethnic Shan living in a big city in the Burman milieu. Walking on the city streets, he is heckled by kids on the street for his peculiar attire: an ethnic Shan outfit. A house driver would ask if he wanted to go to "pya gyi" (a big pagoda) as if he is a country bumpkin who has come to the city for the first time. When he goes to the tea shop, he is asked if he wants more sugar because stereotypically the Burman perceive hill people like the Shan as people who love to eat sweets. When he hangs out near movie theaters, people on the streets who sell the tickets ask if he wants to watch Hollywood action movies. He is insulted because urbanite Burmans perceive hill people as country hicks who get excited when they see machine guns, helicopters, and new technology in those movies. Mandalay Yao Shan Ta Yao is a personal song that reflects the life and experience of a newcomer in a big city.

Although Mandalay Yao Shan Ta Yao talks about discrimination and prejudice from the experience of an ethnic minority, this song broke into the national scene to become one of the biggest hits in Burmese pop music history. While many Shan audiences perceive this song as reflecting the feeling of Shans being looked down upon by the Burman majority, a Burman man explains to me that "it is not that the Burman look down upon the Shan. The persona in the song talks about how funny and clumsy he was in the big city. It is a common experience, and everyone could feel the same." He goes on to say that "when the person in the song goes to the tea shop, the tea shop boy just asks him to come taste our sweetness, come drink my sugar." However, a number of my Shan informants state that they find that this phrase rightly reflects the way the Burman look down upon the Shan through stereotypes of food and drink preference. In fact, like any other forms of expressive culture, Sai Khamlek's message can be interpreted from various angles. While from the Shan audience's point of view, this song is criticizing the stereotypes through which the Shan as hill people are often depicted, the Burman audience could take it as a way to co-opt the prejudice held by the Burman toward other ethnic minorities. Yet, among the Burman audiences, while this particular audience may bring co-optation into reading it, others find this song makes them feel intimate toward the persona in the song. A number of my Burman informants state that they think the persona in the song is "cute." Here we can see that by accepting stereotypes and turning them into self-deprecation, Sai Khamlek has in effect turned prejudice into a realm of intimacy in the responses of several audiences. On the reception level, these multiple interpretations reflect the ways in which audiences of both ethnic groups negotiate notions of Shan-ness in their engagements with a local form of popular music.

Popular music is part of expressive culture which, on one hand, can reveal the complex layers through which expressive culture expresses, resists, and has become embedded within the culture. On the other, it is the process by which social practices are altered, maintained, and entangled with socio-historical production (Williams 1981). In a country like Burma where communication is highly controlled and regulated, it is not surprising that most lyrics are not politically charged. While I do not assume that Sai Khamlek's lyrics often contain political messages conveyed through hidden meanings, I am intrigued that audiences in Burma tend to politicize his songs in their own task of interpretation. Whether or not the songwriter intends to talk about political condition in Burma by using coded content, many of Sai Khamlek's songs are often interpreted as containing political statements by his fans. Ngwe Thoa Tan Si Tho, Tha Gin Da Bod (A Song to Silver Mountain Ranges) is among the many of Sai Khamlek's songs that audience often claim contain veiled political content: 
Why did it happen like this? Only she and I know it

Oh! Silver Mountain Ranges.

Then, your children genuinely loved each other

Amongst them, this couple was a norm.

I did not expect, it would happen like this.

It's sad for the two of them. Oh! Silver Mountain Ranges.

After ten years of waiting, for the moment,

they deserve love and kindness even just for the night,

Before separating each other forever.

Now they are in one another's arms,

Although I am happy for a young lady,

I am worried for the boy from the hill.

It's true that not every couple can be together.

Oh independence! You can't rely on love only.

I remember once my brother had said

Oh! Silver Mountain Ranges

What they want is the rain, but the clouds were wiped away by the wind.

Oh Silver Mountain Ranges

Love was cooled down before being apart,

But it hasn't died. There will be time for this story.

Oh! Independence. It is for a laughter or a cry.

You can't rely on love only.

I remember once my brother had said

Oh! Silver Mountain Ranges.

(composed by Sai Khamlek, n.d.)

This song plays with metaphor. Looking from the encoding side, the use of the words "lowland" and "hill area" as they are commonly used by people to refer to the Burman and the hill people such as the Shan, suggests the audience to think about the Burman from the lowland and the Shan from the hill area. In addition, the relationship between a lowland girl and a hill boy and the 10 years timeframe are the key to guide the audience to interpret the song as referring to the specific historical event in 1947 when the Panglong agreement was signed, followed by the promise that was broken. Many of the Burman audiences, when they learn that I am interested in Sai Htee Saing's songs, often ask me if I know of this song and that this song contains a veiled political meaning. When I ask them what that political meaning is, they explain that the girl represents the Burman and the boy stands for the Shan. The girl promises the boy that she will return, but the promise is broken just like the Burman promise the Shan that they would return independence to the Shan after ten years. The song invokes the spirit of the Panglong Agreement that has not been observed by successive military regimes. Yet, Sai Khamlek's lyrics are always ambiguous as there is no single line in this song clearly indicating this political debate or referring to the relationship between the Shan and the Burman. While ambiguity is the safest approach when addressing political discontent, it simultaneously transfers power into the hands of audience to uncover the meaning from the media text.

Although Sai Khamlek has written more than 1,000 songs and most of them deal with expressions of love, many of his songs explicitly deal with aspects of being Shan under the rule of the Burman. In Tao Paw Mye Yeh, Ta Kha Ta Myen Na (On the Other Side of the Mountain), Sai Khamlek talks about the "front page" of a mountain with beautiful cherry blossoms. The greenery of mountains is depicted in many films, poetry and songs. The audiences only know about the beauty of mountains, and they never realize that there is 
another side of all mountains that is more real. On the "back side" of the mountain, there are different stories where the flowers are ripped out, the smell of the gunfire hangs heavy in the air, and wild trees are burned down indiscriminately.

Beside the use of Shan symbols to talk about politics in Shan state, other songs of Sai Khamlek speak to the theme of Shan sentimentalism. There are sentiments about homeland; longing to go back home, missing Shan food and the smell of cherry blossoms. In Shit Te Shan Yoma (My Beloved Shan Mountain Ranges), Sai Khamlek talks about nostalgia for the Shan homeland, to where he always longs to return.

Only seen from far away, I am not happy.

To the Shan blue mountains, I miss them always,

Yearning forever.

I have not gone back for a long time,

My beloved Shan mountain ranges.

I had studied far away,

Even if I wanted to go back, I can't.

The sound of Shan drums,

The style of Shan dance,

I haven't heard, I haven't seen these for a long time,

My beloved Shan mountain ranges.

In the arms of the motherland,

I was happy with old friends,

Shan sticky rice, Shan fermented beans,

I haven't eaten, I haven't tasted these for a long time.

My beloved Shan mountain ranges.

(composed by Sai Khamlek, n.d.[1980s?], translated by the author)

In Sai Khamlek's lyrics listed above, we can see the way in which social relationships between two ethnic groups are written into cultural forms. Before discussing on his strategic usage of these symbols, let us now turn to Sai Sai Mao's songs. There are both differences and similarities in the strategies of the songs written by Sai Khamlek and Sai Sai Mao, and in the ways in which audiences interpret their songs. While audiences often refer to Sai Htee Saing's songs written by Sai Khamlek in terms of what Scott (1985) has called "hidden transcripts," referring to symbolic expression of socio-cultural discontent by using cloaked sentiment, Sai Sai Mao's songs are viewed as simply nostalgic and romanticizing Shan people. His most famous Burmese song is Shan Pe Po Le Jannaw (I am a Shan Fermented Bean).

In the misty mountain,

Pleasant and cold over the little city.

On simply a visit, you can feel the hospitality, real friendliness.

Oh! If you wish, you can call me a fermented bean. I don't mind.

Because according to Shan tradition, I am a Shan fermented bean,

Friendly to all.

Come visit a cold Shan city again.

I will sing Shan songs,

I will dance traditional Shan dances with all my heart.

In the tea forest, you can have the pleasure of seeing white-skinned Shan girls

Picking tea leaves.

This is our Shan life.

(composed and sung by Sai Sai Mao, n.d.[1980s?], translated by the author) 
In this song, Sai Sai Mao refers to himself as a Shan fermented bean. It is known in Burma that Shan staple food is "thoa nao" (in Shan language) or fermented beans, preserved into a thin round shape. Some Burmese people feel that "Shan pe po" (fermented bean in Burmese language) is smelly whereas Shan people think that Burmese "nga pi" (shrimp paste) has a disagreeable odor. As the Shan eat Shan pe po with every meal and put it into many dishes, people in Burma come to associate the Shan with Shan pe po. Sai Mao, by appropriating this food reference to refer to himself, has turned it into a form of selffashioning, affirming his ethnic identification.

In many of Sai Mao's song, Shan state is represented as female, by a beautiful alluring young woman. Sai Sai Mao articulates Shan-ness in a rather spectacular and exotic manner. In Cherry Pan Leh A-The Pay Meh (I Give My Heart to You, My Cherry), a duo song, Sai Mao woos a young Burman woman by referring to the charming aspects of Shan state and the wholehearted Shan man.

M: Even though the cherries are not in bloom yet, They will make your heart cool forever. Same as the heart of a hill man, Love will never fade away.

$\mathrm{W}$ : Give me gently kiss, Under the shadow of the cherry tree. With a drop of pearl snow in the mist, Don't say anything to break my heart.

M: In the cold climate of Shan state, It's difficult to stay without you.

W: I am coming back, my sweet first love. At least, I have to learn to be able to speak Shan.

M: My golden sweetheart, even the cherry is not in blossom, It will make your heart cool anytime.

W: Oh! My beloved hill man,

M: Same as the heart of a hill man, Love will never fade away.

W: Same as the heart of a hill man, Love will never fade away.

(composed by Sai Sai Mao, n.d., translated by the author)

Audiences often say that they love Sai Sai Mao's songs because of his voice. He has a soft and seductive voice with an accent when he sings in Burmese. The melodies are easy to catch because they are from already familiar Chinese pop songs. Many say they already feel appreciation towards the Shan people, and Sai Mao's lyrics about Shan people fit with their own imagination that Shan people are hospitable and Shan women are beautiful. This can be seen as self-representation that takes forms of self-deprecation and nostalgia for the Shan. In what follows, I shall discuss strategies used by these two artists in two realms of investigation; self-representation and the notion of nostalgia.

\section{In the Realm of Nostalgia and Intimacy}

In Burma, like in other countries in Asia where there are many ethnic minorities, minorities are always portrayed in natural, romantic settings, surrounded by fauna and flora (see Gladney 1999). While minorities are represented as exotic, the majority are always represented as 'normal' and 'un-exotic'. Their normality, civility, and subjectivity help to exoticize others. The Shan who live in the mountainous area have long been presented in 
Burmese paintings, novel and films as existing in natural, romantic settings, and the Shan people are often seen as hospitable and exotic in contrast with the 'normal' Burman. This is very much like Said's thesis in his Orientalism that the Orient is "a place of romance, exotic beings, haunting memories and landscapes, remarkable experiences" (1978:1). But the Shan artists here have moved beyond Said's Orientalism to utilize symbols that once were defined by the dominant discourse for their own task of making themselves. As has been pointed out, both artists have adopted symbols that have been constructed in the Burmese public imagination about the Shan people, such as the cherry flower, Shan mountain ranges, the Salween River, the sound of Shan drums, and tea fields into their songs. Moreover, they have accepted the position assigned to them as "primitive" by calling themselves as "tao paw ta" or "hill people." These "undisturbed natural beauty", smell, sound, temperature and the simplicity and hospitality of "hill people" have now become a predominant aspect of Shan cultural self-representation. The question remains, however: what effects do these artists expect from using these symbols? What are the differences and similarities in the strategies these two singers use and ways in which audiences interpret the songs of both artists? On the audience side, if Shan-ness is evoked through this form of self-fashioning, is it consumed to confirm Burman's superiority?

In attempting to address these questions, I categorize the strategies these artists use and the ways in which audiences respond to their songs with reference to three main aspects: self-essentialism, nostalgic past, and accented voice. First, I would argue, both Sai Htee Saing and Sai Sai Mao use symbols drawn from common representations of Shan people to talk about themselves. Pratt offers a concept that can illuminate Sai Khamlek and Sai Sai Mao's usage of these symbols, which she calls "autoethnography." To Pratt, autoethnography refers to ways in which colonized subjects work to represent themselves in a fashion that engages with the colonizer's own terms (Pratt 1992:7). While subjugated peoples cannot readily control what emanates from the dominant culture, they do determine to varying degrees how much of that culture they absorb into their own, and what they use it for. Here, as we can see, Shan artists have selected and adopted discourses on the Shan people to their own task of creating themselves, thereby turning them into a matter of Shan ethnic identification. Nevertheless, there are differences in their usages of such symbols. Although Sai Khamlek has romanticized an aspect of being Shan in the same way that Sai Sai Mao has done, the symbols already constructed in the dominant discourses about the Shan people allow Sai Khamlek to articulate a critique towards the regime or to talk about the plight of Shan people in a cloaked sentiment. As for Sai Sai Mao, while, in my view, the romanticization of Shanness in Sai Sai Mao's songs is not intended to express ethnic frustration or addressing any desire for change, his "self-deprecation" enables him to reaffirm Shan ethnic identity. It is as Stuart Hall suggests, culture identity is "not an essence but a positioning. Hence, there is always a politics of identity, a politics of position" (Hall 1990: 226). Sai Mao's selfessentialism reflects the construction of Shan identity that takes place in "foreign" language and "foreign" venue which in turn has significant consequences for process of Shan selfproduction.

Both artists have successfully fashioned signs and symbols capable of appealing to members of the dominant community. As Lipsitz (1994) has argued, one cannot transform society by standing outside of it. It is by working through the channels of commercial culture and working through the dominant language that these artists' voices can be heard. The use of Burmese language not only enables them to insinuate its message in the discourse of the dominant, but it also allows them to address specific problems, thereby turning their ethnic 
struggle into a national struggle. Their strategies may involve appropriation, selfessentialism, or self-exoticism (Spivak 1988). But appearances of self-essentialism and appropriation can also provide protective cover for explorations of individual and collective identity. Especially when carried on by members of aggrieved communities - racially marginalized "minorities" - essentialisms enable individuals to address indirectly problems that they could not address directly.

The question which remains is, what it is that audiences consume in the selfessentialism of these two artists? If by making their voices heard, cultural making is taking place; then one must take seriously the audience and its role. As argued, this is not one way of communication. Rather, it is a "contact zone" that treats the relations among two different groups not in terms of separateness, but in terms of co-presence, interaction, interlocking understandings and practices (Pratt 1992: 7). By choosing to perform in a dominant language, using symbols drawn from dominant discourses, Shan artists have transformed popular music into a domain of dialog, providing enough commonality for both parties to pursue their agendas. In Burma where communication is highly regulated and where ethnic languageentertainment forms have been almost absent, it is not surprising that many of Sai Khamlek's songs are interpreted as containing political statement by the Shan audiences. For the Shan fans, Sai Khamlek's lyrics may serve as a tacitly subversive expression of socio-cultural discontent. But what can we then understand from the appropriation and love of Sai Khamlek's songs by the Burman fans? This I would suggest that, on the one hand, the audiences' involvement with his politicizing statements is fostered by the fact that pop culture is Burma fails to serve as a basis for counter-hegemony. As a heavily coded pop, it is not easily translated into direct political action, but for precisely that reason, it retains a freedom of action that enables it to insinuate its message in the discourse of the dominant. On the other hand, the ambiguity in his songs has in effect turned audience interpretations into a game. By using coded messages, Sai Khamlek allows the audience to decode them, thereby finding pleasure in unmasking hidden meanings. It becomes a game among the audience as they attempt to interpret Sai Khamlek's songs in political ways. In one extreme case, I was told by many Burman audiences about the song Be Number OK 0122 L (Bicycle's Tire No. OK $0122 \mathrm{~L}$ ). The song talks about a poor man riding a bicycle with his girlfriend on the back. When the bike gets a flat tire, he discovers that the tire has the number OK $0122 \mathrm{~L}$ written on it. A number of audience members told me that these letters and numbers can be interpreted by switching around the letters and numbers so that it reads as LOOK, KILL and 12/2, which refers to February 12, 1947, the day that Shan princes signed the Panglong Agreement as mentioned earlier. This signing resulted in Shan people being oppressed by the Burmese regime in the present day. Hence we can see that it is in the very ambiguity of Sai Khamlek's songs that enables him to insert a multi-layer of politics into cultural commodities, allowing audiences to interpret them in the contexts of their own experiences and aspiration. The pleasure the audiences take lies in deciphering the critique and combining it with the unspoken, shared community knowledge of what has occurred. It is, therefore, not surprising that Sai Khamlek's songs are constantly being reinterpreted and juxtaposed to the evils of the present system.

Here I would like to turn to my second point, the representation of nostalgic past in the songs of both artists. As argued, both artists have used nostalgia as a form of selfrepresentation. The representation of the past in their songs contains a very specific idea of Shan-ness that it is "a place of romance, exotic beings, haunting memories and landscapes, remarkable experiences" (Said 1978:1). A number of audience members of both Sai Htee 
Saing and Sai Sai Mao tend to express a sense of intimacy towards nostalgia embedded in the songs. They say that they view Shan state as a land of beautiful nature and Shan people as hospitable. As nostalgia often connects to the notions of homeland and loss, Sai Htee Saing's and Sai Sai Mao's songs provide "a place of romance," "undisturbed natural beauty" and a version of distant homeland that feed into the imagination of the Burman audiences. However, while I suggest that the Burman audiences feel nostalgic and longing in the home of the "Other," I do not mean that people are nostalgic for no good reason. As Lipsitz (1994) argues, mass communication texts change the meaning of time, history, and memory because they allow people to experience a common past with other they have never seen, and with a past to which they have no biological or geographical connection. Hence, I would argue, by admiring minority hills, and minority 'Other' as unrestrained and beautiful, that the repressed Burman subject can find a sense of self. The alienation in Burmese society may wax nostalgic over exoticized representations of imagined pasts. Nostalgia of the 'Other' is permissible when it is regarded as less familiar and less civilized that one's own existence (Gladney 1999). Here the Burman find themselves gazing upon the internal Other, engaging in a commodified Orientalism (Said 1978). While minorities may appear to have little choice in the way they have been exoticized in the Burman public mind, here we have an example of Shan singers chosen to co-opt that exoticization. This is a process we might call "strategic essentialism" after Spivak (1988).

From the production side, we can see how language and images are employed as a form of self-representation which allows songwriters and singers to have a dialogue with the audience, both in a political way and a romanticizing way. Form the audience side, nostalgia about the land they have never been to offers a sense of healing for the suffering present. The Shan become a subject for such romantic yearnings.

\section{Conclusion}

Scholars argue that music does not simply "reflect;" rather, it provided the means by which social and political hierarchies are negotiated and transformed (Askew 2002, Averill 1997). Shan musicians and composers constitute a form of cultural expression and a resource through which social and political identities are constructed, contested, reshaped, and manipulated. Popular music does not reveal a utopian narrative of collective identity. It does expose all the contrariness, contradiction, and negotiation that underscore cultural production endeavors.

However, studies of music in relation to ethnic identity are often weakly theorized since the basis of the claim that popular and folk music can represent the constructed national or ethnic collectivities lies in the unique potential of music as a system of "symbolic representation" which is often arbitrary and ambiguous. This kind of approach asks the questions of how, and to what extent, the boundaries of place and self converge through music in a given community, or how individuals, communities, or nations utilize music strategically to locate and even transform concepts of themselves and their territories in relation to other social groups and places (Stokes 1994: 3-5). In claiming that popular music can represent the constructed national or ethnic collectivities, this claim often draws on an identity politics approach arguing that in defending collective identity against the practice of racist society, ethnic consciousness is realized and objectified into an assertive identity. Popular music as well as other forms of art and performances is viewed as part identity politics - that is employed to present an identity which is simultaneously inclusive (to 
insiders) and exclusive (to outsiders). Here we have an example of Shan artists who, instead of drawing boundaries that are inclusive and exclusive, engage in dialogue with those of Burmese representations. As a commercial enterprise established essentially to secure profitable returns on investments, popular music rarely respect the limits of ethnic or national boundaries. It is by adopting dominant discourses as self-representation that their music is carried to a wider audience and allowing them to develop new social relations with possibly profound political implications. Shan musicians do recognize the impossibility of standing outside totalitarian systems of domination and that one cannot transform society by standing outside of it.

\section{Bibliography}

Aung Zaw

2004 "Burma: Music Under Siege" in Marie Korpe ed. Shoot the Singer! Music Censorship Today. London and New York: Zed Boos. Pp.39-61.

Askew, Kelly

2002 Performing the Nation: Swahili Music and Cultural Politics in Tanzania. Chicago: University of Chicago Press.

Averill, Gage

1997 A Day for the Hunter, A Day for the Prey: Popular Music and Power in Haiti. Chicago: University of Chicago Press.

Eberhardt, Nancy

2006 Imaging the Course of Life: Self-Transformation in a Shan Buddhist Community. Honolulu: University of Hawaii.

Frith, Simon

1996 Performing Rites: On the Value of Popular Music. Cambridge and Massachusetts: Harvard University Press.

Hall, Stuart

1990 "Cultural Identity and Diaspora." In Jonathan Rutherford ed. Identity: Community, Culture, Difference. London: Lawrence and Wishart.

Gladney, Dru

1999 "Representing Nationality in China: Refiguring Majority/Minority Identities" In Kosaku Yoshino ed. Consuming Ethnicity and Nationalism: Asian Experiences. Honolulu: University of Hawaii Press. Pp.48-88.

Lipsitz, George

1994 Dangerous Crossroads: Popular Music, Postmodernism, and the Poetics of Place. New York: Verso.

Maung Tin Mya

1984 "Politics and Religion Over-Ruled as Rock Takes Root in the Ricefields" Far Eastern economic review, 12 January: 45-6. 
Min Zin

2002 "Burmese Pop Music: Identity in Transition" The Irrawaddy 10(7): 22-25.

Pratt, Mary Louise

1992 Imperial Eyes: Travel Writing and Transculturation. London and New York: Routledge.

Sai La

1997 "Interview with Sai Khamlek” Shan Magazine Vol.2 (in Shan).

Said, Edward

1979 Orientalism. New York: Vintage Books.

Scott, James

1985 Weapons of the Weak: Everyday Forms of Peasant Resistance. New Haven: Yale University Press.

Spivak, Gayatri Chakrovorty

1988 "Subaltern Studies: Deconstructing Historiography" In Other Worlds. New York: Routledge.

Stokes, Martin

1994 "Introduction: Ethnicity, Identity and Music", In Martin Stokes ed. Ethnicity, Identity and Music: The Musical Construction of Place. Providence: Berg.

Williams, Raymond

1981 The Sociology of Culture. New York: Schocken Books. 